\title{
Fundamentals and role of intravascular ultrasound in percutaneous coronary intervention
}

\author{
James $\mathrm{Xu}^{1,2}$, Sidney $\mathrm{Lo}^{1,2}$ \\ ${ }^{1}$ Department of Cardiology, Liverpool Hospital, Sydney, NSW, Australia; ${ }^{2}$ South Western Sydney Clinical School, University of NSW, Sydney, \\ NSW, Australia \\ Contributions: (I) Conception and design: All authors; (II) Administrative support: All authors; (III) Provision of study materials or patients: None; \\ (IV) Collection and assembly of data: J Xu; (V) Data analysis and interpretation: J Xu; (VI) Manuscript writing: All authors; (VII) Final approval of \\ manuscript: All authors. \\ Correspondence to: Dr. James Xu. Department of Cardiology, Level 1 CSB, Liverpool Hospital, NSW 2170, Australia. Email: james.xu@unsw.edu.au.
}

\begin{abstract}
Intravascular ultrasound (IVUS) is a catheter-based invasive imaging modality that has become an essential adjunctive tool to percutaneous coronary intervention (PCI) over the past 20 years. Clinical applications of IVUS in PCI include assessment of lesion severity, characterizing plaque morphology, optimization of acute stent results and clarification of mechanisms of stent failure. Numerous meta-analyses of large observational and randomized studies support the role of IVUS-guided PCI in reducing short and long-term adverse outcomes, including mortality and stent failure, particularly in patients receiving drug-eluting stents (DESs) and in complex lesion subsets. The current review provides a summary of the fundamental aspects and current clinical roles of IVUS in coronary intervention.
\end{abstract}

Keywords: Intravascular ultrasound (IVUS); percutaneous coronary intervention (PCI); drug eluting stent

Submitted Dec 14, 2019. Accepted for publication Jan 15, 2020.

doi: $10.21037 / \mathrm{cdt} .2020 .01 .15$

View this article at: http://dx.doi.org/10.21037/cdt.2020.01.15

\section{Introduction}

Supported by a wealth of randomized and observational data, intravascular ultrasound (IVUS) has established itself as an invaluable adjunctive tool to contemporary coronary angiography and percutaneous coronary interventions (PCI). Indeed, in the current drug-eluting stent (DES) era, IVUS-guided PCI has consistently been shown to reduce hard clinical endpoints of mortality, target lesion revascularization, stent thrombosis and myocardial infarction (MI), across various lesion subsets and device generations $(1,2)$. Recently, the 2-year exploratory analysis of the SYNTAX II study (3), where IVUS was used in $84 \%$ of cases, re-affirmed earlier observations that this "state-ofthe-art" PCI strategy utilizing modern adjunctive tools such as IVUS, can achieve superior clinical outcomes compared to angiography-guided PCI and even coronary artery bypass grafting (CABG).

However, despite a firmly established evidence base and guideline endorsements, utilization of IVUS in routine interventional practice remains highly heterogenous and is underscored by substantial variability in regional practices and individual operator experience (4). Cost remains a major factor in many countries. Appropriate knowledge exchange, stronger guideline-driven indications and reimbursement for IVUS use are key to improving its clinical penetration. The purpose of this review is to provide a concise summary on the clinical applications of grayscale IVUS and to highlight its extraordinary potential to enhance interventional practice.

\section{Image evaluation: the fundamentals}

The principles of IVUS are analogous to other forms of ultrasound imaging: piezo-electric crystals generate ultrasound pulses under electric current, and reflected echoes from tissue structures are used to produce monochrome images in grayscale. More reflective or 
echogenic structures such as fibrous tissue and calcifications produce brighter signals, whereas echo-lucent structures such as lipid collections generate low-intensity signals. As with all ultrasound techniques, measurements on IVUS images are obtained from leading-edge to leading-edge as a standard approach.

The spatial resolution of IVUS is dependent on the wavelength and beam-width of the ultrasound pulses. The lower the wavelength and narrower the beam width, the better the axial and lateral resolution, respectively. Both variables can be altered by varying the frequency of the transducer. Frequency is related to wavelength by the equation: $c=f \lambda$, where $c$ is the speed of sound which is constant, $\mathrm{f}$ is frequency and $\lambda$ is wavelength. Therefore, as frequency increases, wavelength and beam-
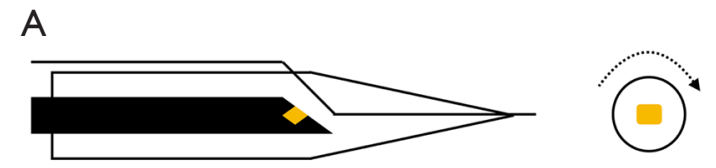

B
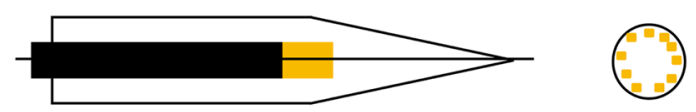

Figure 1 Types of IVUS catheters. (A) Mechanical rotational or annular array with a rotational transducer; (B) phased-array with multiple fixed transducers. IVUS, intravascular ultrasound. width are reduced, increasing axial and lateral resolution. Tissue penetration is another factor that is determined by frequency. As frequency is increased, penetration distance is decreased. These factors need to be considered when selecting the IVUS catheter.

There are two main types of conventional IVUS catheters used in clinical practice today: mechanical rotational single transducer probe (annular-array) with a typical sound frequency of $40-45 \mathrm{MHz}$ (such as OptiCross ${ }^{\mathrm{TM}}$, Boston Scientific, USA), and phased-array probe with multiple fixed transducers with a typical sound frequency of $20 \mathrm{MHz}$ (such as Eagle Eye ${ }^{\mathrm{TM}}$, Philips Volcano, USA) (Figure 1). Image pull-backs can be performed manually or automatically with a typical pull-back speed of $0.5 \mathrm{~mm} / \mathrm{s}$. Catheters range from 2.6-3.5 French and can therefore be placed through 5 or 6 French guiding catheters, depending on the IVUS catheter used (5) (Table 1). The typical axial resolution for commonly used systems is $\sim 80-100 \mu \mathrm{m}$ and lateral resolution is $~ 200$ $250 \mu \mathrm{m}$, whereas tissue penetration is $\sim 6-12 \mathrm{~mm}$ (6). More recently, high-definition IVUS with transducer frequency of $60 \mathrm{MHz}$ has also become available, allowing for superior axial resolution $<40 \mu \mathrm{m}$. To put this into context, modern thin-strut stents typically have a strut thickness of $60-80 \mu \mathrm{m}$.

Image artifacts are frequently encountered and important to recognize. Many IVUS artifacts are also present in other forms of ultrasound imaging and have similar underlying principles. These include: reverberation artifacts, acoustic shadowing and ring-down artifacts. A more unique IVUS artifact is the non-uniform rotational

Table 1 Characteristics of selected IVUS catheters

\begin{tabular}{|c|c|c|c|c|c|c|}
\hline Characteristics & $\begin{array}{c}\text { Boston Scientific } \\
\text { OptiCross }\end{array}$ & Philips Volcano Eagle Eye & $\begin{array}{l}\text { Philips Volcano } \\
\text { Revolution }\end{array}$ & $\begin{array}{l}\text { Philips Volcano } \\
\text { Refinity }\end{array}$ & $\begin{array}{c}\text { Acist } \\
\text { Kodama }\end{array}$ & $\begin{array}{l}\text { Terumo } \\
\text { ViewlT*}\end{array}$ \\
\hline Transducer frequency & $\begin{array}{c}40 \mathrm{MHz}(60 \mathrm{MHz} \mathrm{HD} \\
\text { version also available) }\end{array}$ & $20 \mathrm{MHz}$ & $45 \mathrm{MHz}$ & $45 \mathrm{MHz}$ & $60 \mathrm{MHz}$ & $40 \mathrm{MHz}$ \\
\hline Distal shaft profile & $3.1 \mathrm{~F}$ & $3.3 \mathrm{~F}$ & $3.2 \mathrm{~F}$ & $3.0 \mathrm{~F}$ & $3.2 \mathrm{~F}$ & $2.6 \mathrm{~F}$ \\
\hline Proximal shaft profile & $3.1 \mathrm{~F}$ & $2.9 \mathrm{~F}$ & $3.5 \mathrm{~F}$ & $3.0 \mathrm{~F}$ & $3.6 \mathrm{~F}$ & $3.2 \mathrm{~F}$ \\
\hline $\begin{array}{l}\text { Guiding catheter } \\
\text { compatibility }\end{array}$ & $\geq 5 \mathrm{~F}$ & $\geq 5 \mathrm{~F}$ & $\geq 6 \mathrm{~F}$ & $\geq 5 \mathrm{~F}$ & $\geq 6 \mathrm{~F}$ & $\geq 5 \mathrm{~F}$ \\
\hline Comments & $\begin{array}{l}\text { Rotational (annular } \\
\text { array), OptiCross HD } \\
\text { has highest IVUS } \\
\text { axial resolution }\end{array}$ & $\begin{array}{c}\text { Phased-array, plug-and-play, no } \\
\text { preparation required, } \\
\text { virtual-histology, Chromaflo }\end{array}$ & Rotational & Rotational & Rotational & $\begin{array}{l}\text { Rotational, } \\
\text { excellent } \\
\text { crossing } \\
\text { profile }\end{array}$ \\
\hline
\end{tabular}

*, not available outside of Japan. HD, high-definition; IVUS, intravascular ultrasound. 

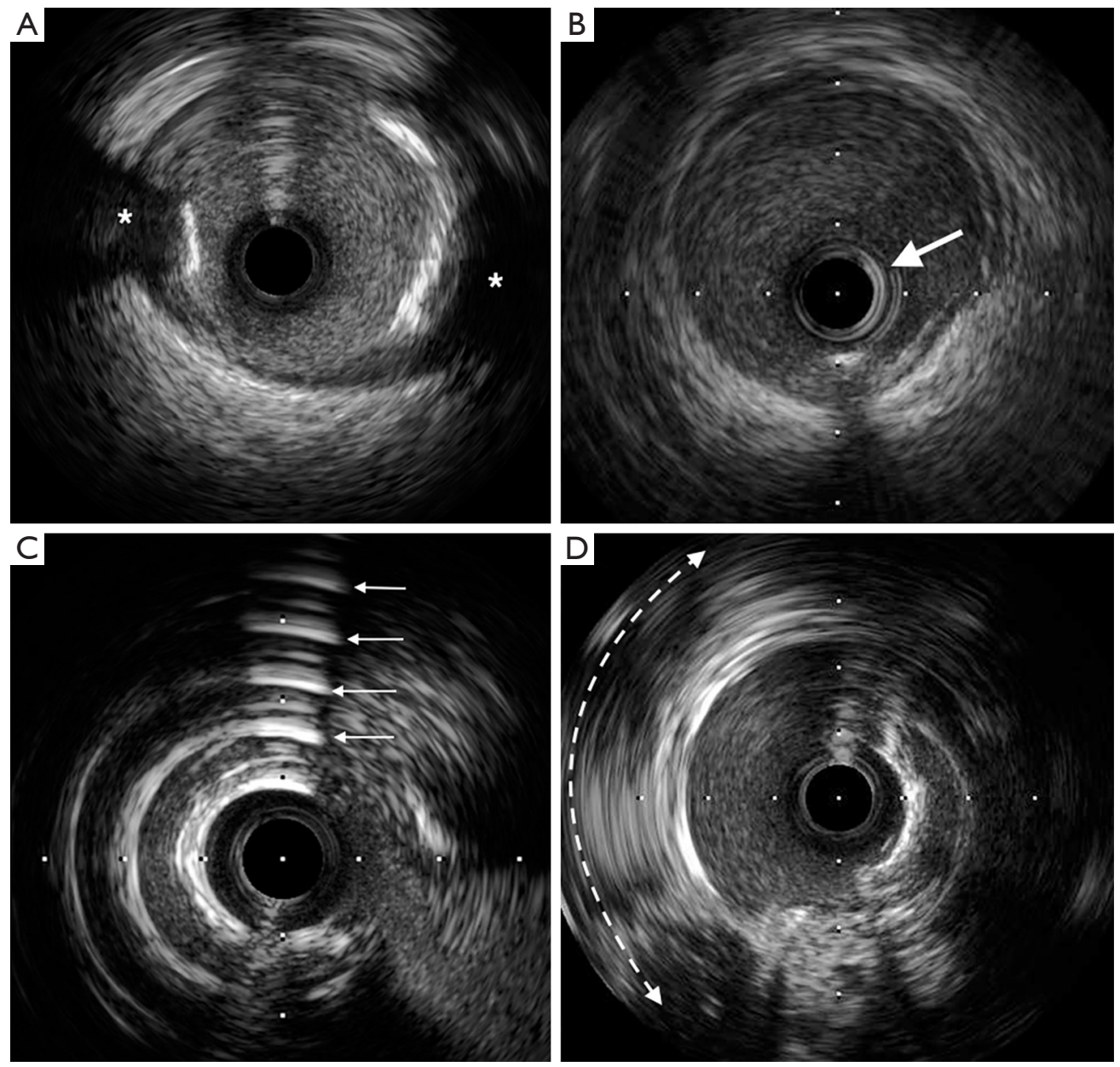

Figure 2 Examples of IVUS artifacts. (A) Acoustic shadowing behind calcific plaque (Asterix); (B) ring-down artifact seen as a bright ring around the IVUS catheter (arrow); (C) reverberation artifact seen as multiple equidistant reflections from calcium (multiple arrows); (D) NURD (non-uniform rotational distortion) is seen between 7 to 12 o'clock (curved dotted arrow). IVUS, intravascular ultrasound.

distortion (NURD) (Figure 2), which is exclusive to the mechanical rotational IVUS systems. This often occurs as a result asymmetric friction due to bends in the artery and guiding catheter or over-tightening of Tuohy-Borst on the catheter resulting in cyclic geometric distortion of the image (6). Since air reflects ultrasound before it can reach tissue structures, air-bubble artifacts can degrade and potentially obliterate the IVUS image, hence meticulous catheter preparation with flushing is mandatory prior to imaging. Therefore, catheter flushing during pullbacks is conceptually a coronary artery air embolism risk, which is best avoided by re-flushing outside the body. A detailed discussion of the various types of ultrasound artifacts is beyond the scope of this review.

\section{Lesion assessment}

\section{Significance of stenosis}

The DEFER, FAME and FAME 2 trials, all with longterm follow-up data, not only established fractional flow reserve (FFR) as the standard of reference for assessing the hemodynamic significance of coronary stenoses, but also cemented the paradigm that angiographic and physiologic assessments of stenosis severity are poorly correlated (7-9). By extension, it should not come as a surprise that IVUS minimal lumen area (MLA) measurements, a purely anatomic assessment, is also only a modest correlate of FFR. This is not to say, however, that there is no role for IVUS in this context, especially in the case of left main coronary 
artery (LMCA) lesions, where FFR may have certain caveats and limitations.

Numerous studies have evaluated optimal IVUS MLA cut-offs that best correlate with FFR. A wide range of values have been proposed and studies have variably validated against an FFR cut-off of either 0.75 or 0.80 . In general, reported optimal MLA cut-off ranges are $2.1-4.4 \mathrm{~mm}^{2}$ for non-LMCA lesions, and 4.5-6.0 $\mathrm{mm}^{2}$ for LMCA lesions, with typically smaller MLA values in studies performed in Asian countries (10). As a rule of thumb, many clinicians use a non-LMCA MLA cut-off of $4.0 \mathrm{~mm}^{2}$ and LMCA MLA cut-off of $6.0 \mathrm{~mm}^{2}$ to determine if revascularization is warranted. It should be noted that while deferring PCI based on these thresholds may be associated with favorable long-term clinical outcomes $(11,12)$, these should not be used to justify intervention, unless substantiated by FFR, due the overall high negative predictive value and low positive predictive value of MLA cut-offs reported by most IVUS studies (10).

\section{Plaque characteristics}

Under-prepared calcific coronary lesions are widely acknowledged to be strongly predictive of stent delivery failure and stent under-expansion. Recognizing calcified plaque is important in selecting appropriate adjunctive treatment strategies, such as rotational atherectomy, prior to stent implantation. Not only is IVUS superior to angiography for detecting calcified plaque, it can be used to objectively quantify calcium according to the angle subtended by the calcified arc and its longitudinal length, the product of which has been described as the calcium index, which has been used to help categorize the extent of calcification (13). In practice, these parameters can help determine the extent of plaque modification required and the likelihood of peri-procedural enzyme elevations $(14,15)$.

Non-calcific plaques can be broadly grouped into soft or hard. Soft plaques are lipid-rich and therefore echolucent. Hard plaques are fibrous plaques which have greater echogenicity than the surrounding adventitia, but do not typically cause bright echoes and acoustic shadowing characteristic of calcific plaques (Figure 3). Mixed plaques are also seen and these can be fibrocalcific or fibro-fatty (6). Characterizing plaque types with IVUS may have useful clinical implications and provide important insights. For instance, hard plaques may prompt the use of cutting balloons, and soft plaques, although easier to compress with stenting, are independent predictors of in-stent restenosis (16). In fact, highly lipid-rich plaques, especially within large positively-remodelled vessels, are associated with microembolization and no-reflow after PCI in the setting of acute MI (17).

Quantification of plaque burden or percent atheroma volume, a concept distinct from luminal stenosis, can also be achieved with IVUS. Plaque burden is defined as the ratio of atheroma area to the vessel external elastic lamina (EEL) area, where the atheroma area is given by the difference between the EEL area and the lumen area (Figure 4). The extent of baseline plaque burden and its progression has been shown to have a direct relationship with long-term major adverse cardiovascular events (MACE) (18). The PROSPECT study showed that in patients presenting with acute coronary syndromes (ACS), non-culprit lesion plaque burden of $\geq 70 \%$ was associated with long-term MACE (19). Although predominantly done in the research setting, radiofrequency plaque analysis with virtual histology IVUS can aid in the detection of thin-cap fibroatheromas (TCFA). Indeed, large plaque burden $(\geq 70 \%)$ TCFAs have also been shown to strongly predict MACE, even within 6 months, and are higher risk than smaller TCFAs (20).

\section{Guidance of stent implantation}

Through optimization of acute stent results, IVUS-guided PCI has consistently been shown to improve clinical outcomes. Apart from understanding plaque characteristics and modification, IVUS can also aid in identifying optimal stent landing zones, selecting appropriate stent sizes, and minimizing stent under-expansion and mal-apposition.

\section{Pre-stenting}

Post-interventional residual plaque burden has long been acknowledged as a powerful independent predictor of restenosis (21), and this is particularly true where the residual plaque burden at the stent margins is $>50 \%$ (22). This is further corroborated by the observation that angiographically "normal" coronary arteries still tend to have an average plaque burden of 50\% (23). Therefore, a step-wise approach to optimal stent landing, aiming for an IVUS derived normal segment or if not possible then a plaque burden of $<50 \%$, has been proposed and widely adopted (24).

A correct understanding of plaque distribution can also have important implications for pre-intervention planning, 

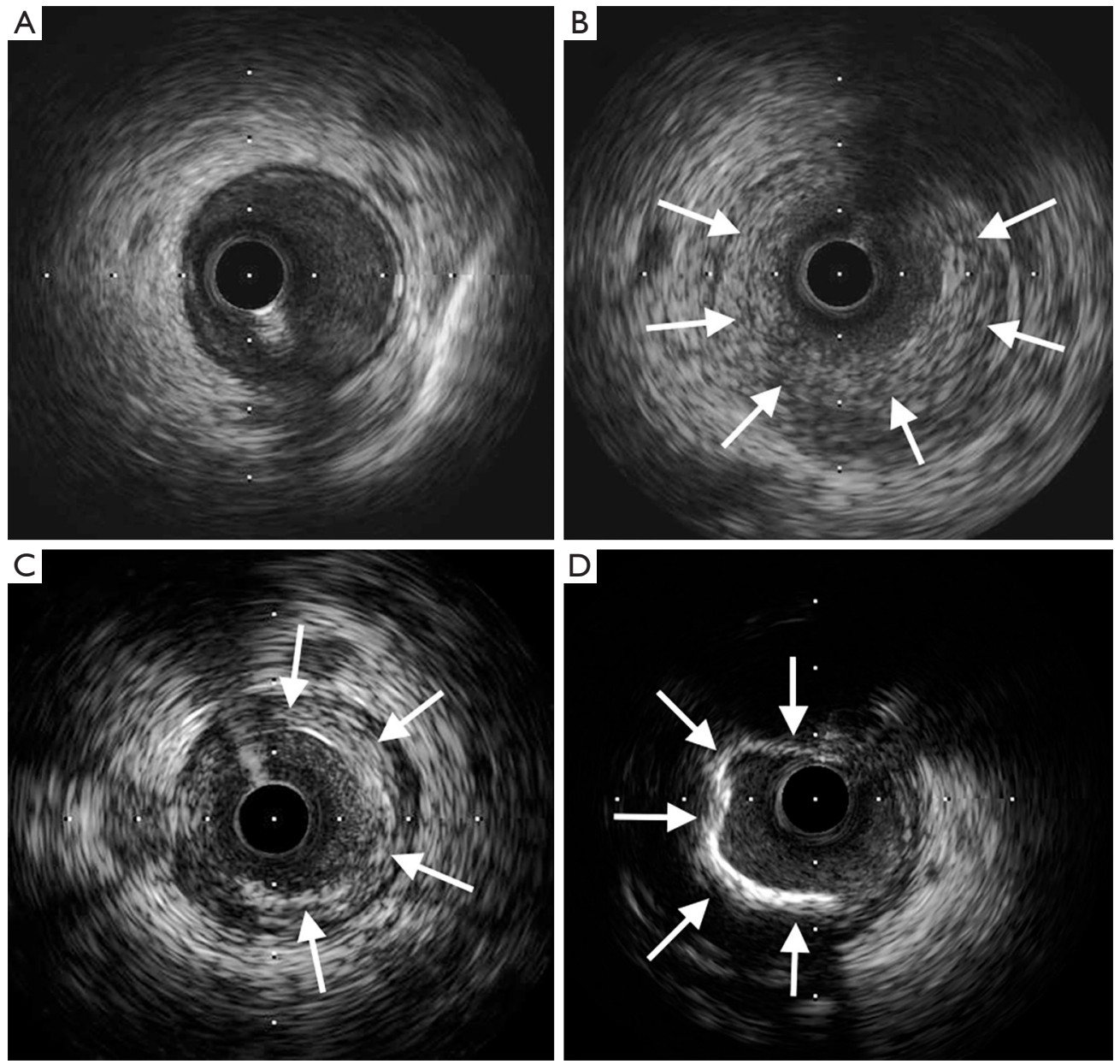

Figure 3 Appearance of different plaque types on IVUS. (A) Normal; (B) soft plaque (arrows); (C) hard plaque (arrows); (D) calcific plaque (arrows). IVUS, intravascular ultrasound.

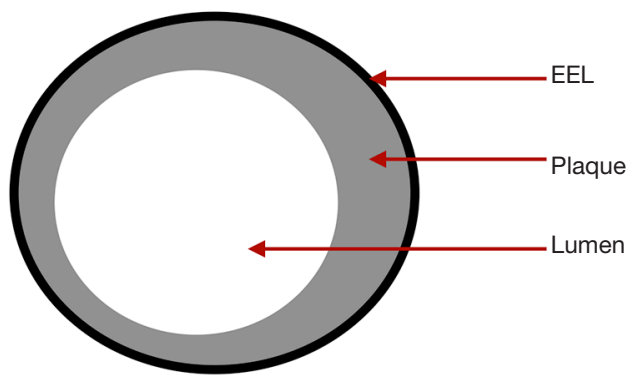

Plaque area $=\mathrm{EEL}$ area - Lumen area

Plaque burden $=\frac{\text { Plaque area }}{\mathrm{EEL} \text { area }}$

Figure 4 Deriving plaque burden. EEL, external elastic lamina. given the limitations of two-dimensional angiography, particularly in key anatomic locations such as the LMCA bifurcation. Indeed, we have come to understand from IVUS analyses that atherosclerotic LMCA disease frequently manifests as diffuse axial plaque involving the distal bifurcation, and the overwhelming majority of distal LMCA bifurcation lesions extend into the proximal leftanterior-descending artery (25). Furthermore, eccentric plaque distribution can be defined using an IVUS eccentricity index (ratio of maximum to minimum plaque plus media thickness), which may be useful in planning certain procedures such as directional atherectomy, particularly given that angiographic assessment of lesion eccentricity is not a reliable predictor of eccentric plaque distribution (26).

Given the superior tissue penetration of IVUS, 
Table 2 Various IVUS criteria for optimal stent deployment

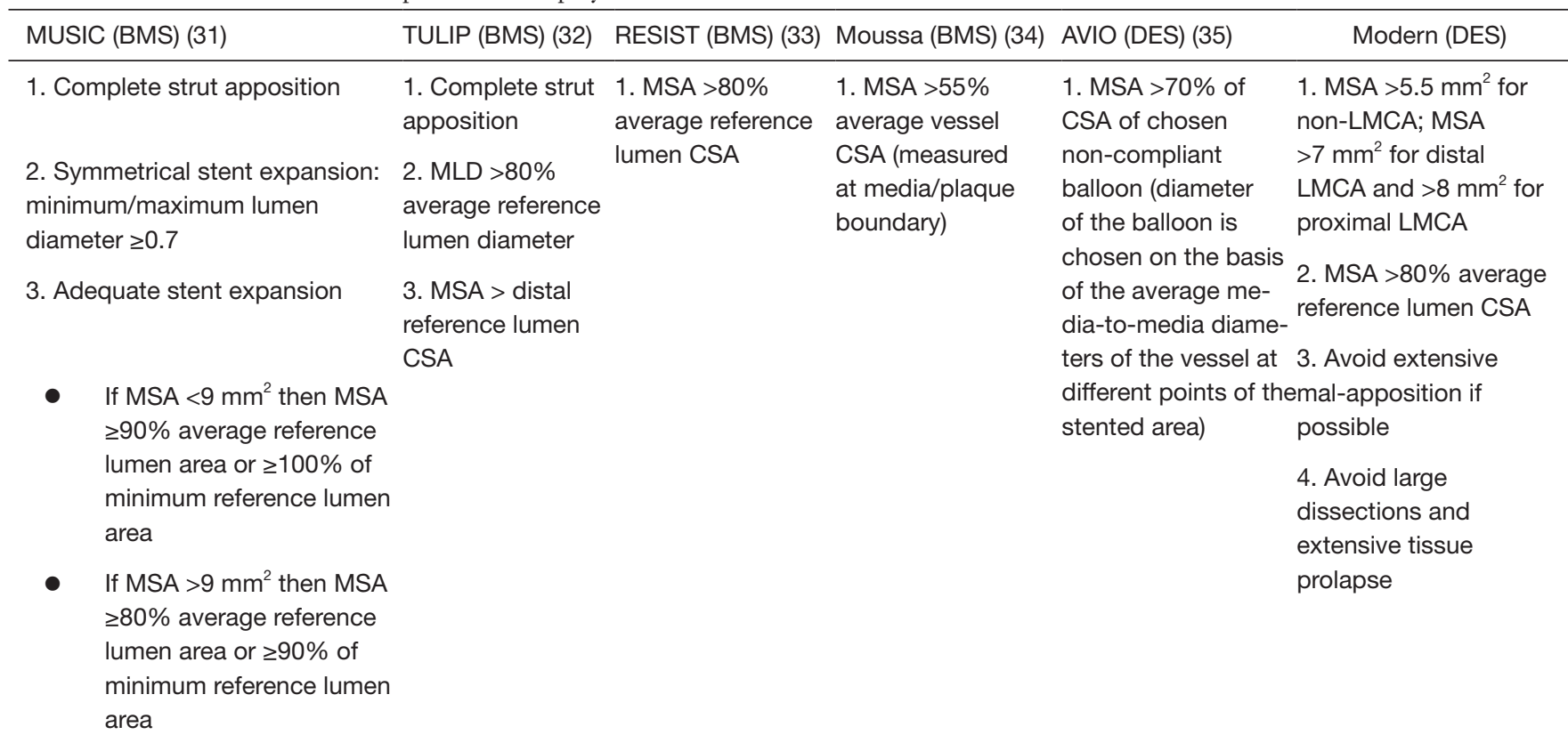

BMS, bare metal stent; DES, drug-eluting stent; MSA, minimum stent area; MLD, minimum lumen diameter; CSA, cross-sectional area; LMCA, left-main coronary artery.

true vessel sizing and detection of positive or negative remodelling is possible, even in larger vessels, allowing for appropriate stent sizing. Different sizing approaches can be used and tend to vary among studies and clinicians. These include, with increasing aggressiveness, lumen, mid-wall or EEL based sizing. The European Association of Percutaneous Cardiovascular Interventions (EAPCI) recommends a practical approach using the mean diameter of the distal vessel reference. Specifically, if a conservative lumen-based sizing is adopted, then the stent size may be up-rounded by $0-0.25 \mathrm{~mm}$, whereas if a more aggressive EEL-based sizing is chosen, then the stent size may be rounded down to the nearest $0.25 \mathrm{~mm}$ stent size (27).

\section{Post-stenting}

Several abnormal post-PCI IVUS features have been identified as predictors of stent thrombosis, including stent under-expansion, persistent mal-apposition (but not isolated acute mal-apposition), large edge dissections, and tissue prolapse (28-30). Among these, stent under-expansion, with a resultant smaller minimum stent area (MSA), was most clearly established as a major determinant of early and late stent failure. The MUSIC study inaugurated a formal IVUS criteria for optimal stent result after bare-metal stent
(BMS) PCI. In this prospective observational IVUS study of 155 stable patients, all 3 proposed criteria for optimized stent deployment were attained in $81 \%$ of patients (Table 2). These patients were treated with single agent aspirin only after stenting, despite which the overall stent thrombosis rate was $1.3 \%$ at 6 months (31). Many subsequent IVUS studies of BMS PCI also applied this or similar criteria, but with highly variable rates of actually satisfying these. For instance, in the AVID trial, the largest of such trials, where 800 stable patients were randomized to angiography or IVUS-guided therapy, a simplified IVUS criteria for optimal stent placement was used, but only achieved in $48 \%$ of IVUS patients (36). In contrast, in the randomized TULIP trial of 150 stable patients, a similar simplified IVUS criteria was used and was achieved in $89 \%$ of IVUS patients (32). Despite this variability, studies were mostly still in favor of IVUS. A meta-analysis of randomized IVUS-guided BMS PCI studies concluded that IVUSguidance improves the MSA and thereby reduces restenosis, repeat revascularization and MACE (37).

The MUSIC criteria was clearly difficult to completely fulfil even in the trial setting, let alone in practice. Studies in the DES era, despite often using much more simplified IVUS criteria for optimal PCI, have similarly highlighted this issue, with large randomized trials such as IVUS- 
XPL and ULTIMATE only fulfilling pre-defined criteria in approximately $50 \%$ of patients $(38,39)$. Furthermore, these criteria often differed widely between studies and were sometimes poorly defined. Nevertheless, studies were largely consistent in that even "sub-optimal" IVUS-guided DES PCI still leads to more aggressive post-dilatation and a larger MSA, and improves clinical outcomes and hard endpoints compared to angiography-guided PCI.

A universal, evidence-based, practical and more consistently achievable IVUS criteria for optimal PCI is still clearly desirable. Observations from earlier generation DES studies suggested that an MSA $<5.0-5.5 \mathrm{~mm}^{2}$ in nonLMCA, $<6 \mathrm{~mm}^{2}$ in ostial LAD, $<7 \mathrm{~mm}^{2}$ in distal LMCA and $<8 \mathrm{~mm}^{2}$ in LMCA trunk best predicted subsequent adverse events (40-42). While large residual stent edge dissections and tissue protrusion also predicted subsequent stent thrombosis, acceptable limits are less precisely characterized. Based on available data, extensive dissections with $>60^{\circ}$ arc, $>2 \mathrm{~mm}$ longitudinal extension, or involving the media or adventitia should be avoided $(29,43,44)$. Any dissection or tissue protrusion resulting in an MLA of $<4 \mathrm{~mm}^{2}$ is also considered extensive and should be considered as a suboptimal result (43). In contrast, the clinical relevance of acute stent mal-apposition, although undesirable, is much more ambiguous. The EAPCI recommends avoiding and if possible, correcting extensive acute stent mal-apposition $>0.4 \mathrm{~mm}$ with longitudinal extension $>1 \mathrm{~mm}$ (27). Table 2 summarizes the above as the generally accepted modern IVUS criteria for optimal DES PCI.

\section{Complex lesion subsets}

Clinical benefits of IVUS may be even more pronounced in complex interventions. In the MAIN-COMPARE study, where IVUS-guided stenting was used in over $77 \%$ of PCI patients, notwithstanding that BMS were used in nearly a third of cases, PCI for unprotected LMCA was comparable to $C A B G$ with regards to all-cause death and a composite endpoint of death, MI or stroke at 10 years (45). In a propensity score matching analysis of 201 matched pairs of PCI patients from MAIN-COMPARE, IVUS guided DES PCI impressively resulted in approximately $60 \%$ reduction in all-cause mortality at 3 years compared to angiography guidance (46). In non-LMCA bifurcation lesion PCI, a propensity score matching analysis of 487 pairs of patients from a Korean registry showed that IVUS-guided DES PCI was also associated with a significantly lower incidence of death or MI compared to angiography guidance only (47). Furthermore, in bifurcation PCI, a pre-intervention sidebranch ostium MLA of $>2.4 \mathrm{~mm}^{2}$ is sensitive in predicting a side-branch FFR $\geq 0.80$ after main branch cross over stenting (48). Therefore, IVUS pull-back examination is recommended in bifurcation PCI, and especially in LMCA lesions where defining the anatomy is extremely useful when deciding on the side-branch strategy.

Intravascular imaging is an indispensable tool for chronic total occlusion (CTO) PCI, with IVUS being the most commonly used imaging modality (49). Applications include resolving proximal cap ambiguity (commonly from a sidebranch), delineating proximal cap morphology, confirming the location of wires with respect to the true lumen, and IVUS-guided wiring (50). Specific advantages of IVUS include the lack of need for antegrade injections, ability to provide real-time 3-dimensional orientation, and the availability of short-tip catheters. In a series of 31 patients with one or more native vessel CTO, where 22 patients had previously failed PCI attempts, IVUS-guided reverse controlled antegrade and retrograde tracking allowed successful CTO recanalization in all cases (51). A novel 3 -dimensional antegrade wiring technique using realtime IVUS has also been developed which has been shown to improve success rate and reduce procedure time of antegrade wiring compared to conventional method (52). In the randomized trial setting, the CTO-IVUS study demonstrated a reduction in 12-month MACE with IVUSguided CTO intervention compared to angiographyguidance only (53), and the AIR-CTO trial, although under-powered for clinical outcomes, showed a reduction in late lumen loss also in favor of IVUS-guided CTO intervention (54).

\section{Research utility}

In the early 1990s, IVUS studies taught us that the risk of early stent thrombosis was more attributable to inadequate stent expansion rather than inadequate periprocedural anticoagulation, and the use of high-pressure postdilatations significantly reduced stent thrombosis rates (55). Furthermore, early IVUS observations provided us with the understanding that restenosis after balloon angioplasty is due to vessel wall negative remodeling rather than cellular proliferation (56), hence the success of stent implantation in reducing restenosis. The use of IVUS in the REVERSAL, ASTEROID and more recently GLAGOV study provided the insight that intensive lipid-lowering treatment reduced 
Table 3 IVUS versus OCT

\begin{tabular}{ll}
\hline Favors IVUS & Favors OCT \\
\hline Aorto-ostial lesions & Thrombus detection \\
CTO PCI & Better detection of finer details due to superior resolution (such as edge dissections, \\
& strut malapposition, tissue protrusion) \\
Renal impairment & Visualization and characterization of calcified plaques \\
Large vessels (>3.75 mm diameter) & Automated measurements \\
Real-time imaging & \\
\hline
\end{tabular}

CTO, chronic total occlusion; $\mathrm{PCl}$, percutaneous coronary intervention.

plaque progression and may even promote regression (57-59). Second generation IVUS techniques such as radiofrequency tissue characterization and near-infrared spectroscopy are able to provide even more detailed information about plaque progression and its response to various treatments, as well as detection of vulnerable plaques and evaluation of stent performance. In the ABSORB study for instance, IVUS radiofrequency analysis allowed better understanding of changes in plaque tissue composition over time (60). As technologies and therapies continue to evolve, IVUS will undoubtedly remain a valuable tool in research.

\section{Safety}

As with any other forms of vessel instrumentation, IVUS examination is not without risks. These can range from vessel dissection to perforation and other potentially lifethreatening complications. The most common complication may be vascular spasm, hence the routine administration of intra-coronary nitrates prior to imaging, and major complication rates, such as dissections, acute occlusion and ventricular arrhythmias occur in approximately $0.1 \%$ of cases (61). The often crucial peri-interventional information provided by IVUS, as well as other potential benefits such as reduced contrast use and radiation, should contextualize this minor increase in acute clinical risk.

\section{IVUS versus optical coherence tomography (OCT)}

A comparison between IVUS and OCT is often made and clinicians may prefer one imaging modality over the other. In reality, OCT and IVUS utilize different technologies to produce intracoronary images. Although the ILUMIEN 3 study suggests that OCT-guided PCI is at least equal to IVUS-guided PCI in achieving a satisfactory MSA (62), each modality has its own advantages and disadvantages and therefore, the two should be considered complimentary. For example, OCT has superior axial resolution (10-20 $\mu \mathrm{m})$ and has the ability to better delineate calcified plaques without artifacts, whereas IVUS has greater tissue penetration and is better at assessing vessel remodeling. Furthermore, the need for increased contrast use in OCT means that IVUS is favored in patients with renal impairment. In addition, forceful injection of contrast can extend and enlarge a dissection plane, limiting the use of OCT in CTO PCI. Table 3 summarizes the clinical scenarios which may favor one modality over the other.

\section{Conclusions}

Despite clear evidence for benefit, IVUS use in PCI is still not class I recommendation in current guidelines (Table 4). Considerations were given to the significant observational data contribution in the meta-analyses and possible treatment selection bias, but the reality may be a combination of this and other factors, such as cost barriers and a perceived increase in duration and complexity of the procedure. As PCI continues to encompass increasingly complex patient and disease subsets, IVUS will become a more integral part of coronary interventions (Table 5). Furthermore, IVUS is a useful tool for research, from evaluating efficacy of various invasive or non-invasive treatments, to understanding mechanisms of stent failure. Second generation techniques such as radiofrequency tissue characterization, nearinfrared spectroscopy and iMap have also matured beyond the research setting in being able to quantify individual plaque components and detecting vulnerable plaque. Device technologies will continue to evolve and hopefully further improve ease of use in practice. The important role of IVUS in contemporary PCI is indisputable, and its underutilization is rapidly becoming inexcusable. 
Table 4 Current guideline recommendations on use of IVUS

\begin{tabular}{lll}
\hline AHAVACC & ESC \\
\hline Ila B & Assessment of angiographically indeterminant LMCA lesions & Assess the severity of unprotected LMCA lesions \\
& $\begin{array}{l}\text { 4-6 weeks and 1 year after cardiac transplantation to exclude } \\
\text { donor CAD, detect rapidly progressive allograft vasculopathy, } \\
\text { and provide prognostic information }\end{array}$ & Optimise treatment of unprotected LMCA lesions \\
Ila C & Determine mechanism of stent restenosis & Detect stent-related mechanical problems leading to restenosis \\
Ilb B & $\begin{array}{l}\text { Assessment of non-LMCA with angiographically intermediate } \\
\text { stenoses }\end{array}$ & \\
& $\begin{array}{l}\text { Guidance of coronary stent implantation, particularly in cases of } \\
\text { LMCA stenting }\end{array}$ \\
Ilb C & Determine mechanism of stent thrombosis
\end{tabular}

LMCA, left-main coronary artery; CAD, coronary artery disease.

Table 5 Uses of IVUS in contemporary PCI

\begin{tabular}{|c|c|}
\hline Indications & Comments \\
\hline Indeterminate lesions & FFR gold-standard \\
\hline Plaque characterization & Plaque morphology, composition, vulnerable plaque \\
\hline \multicolumn{2}{|l|}{ Plaque burden } \\
\hline \multicolumn{2}{|l|}{ Stenting } \\
\hline \multicolumn{2}{|l|}{ Stent sizing } \\
\hline \multicolumn{2}{|l|}{ Stent length } \\
\hline \multicolumn{2}{|l|}{ Landing zone assessment } \\
\hline \multicolumn{2}{|l|}{ Strut apposition } \\
\hline \multicolumn{2}{|l|}{ Edge dissection } \\
\hline \multicolumn{2}{|l|}{ Tissue protrusion } \\
\hline \multicolumn{2}{|l|}{ Mechanisms of stent failure } \\
\hline \multicolumn{2}{|l|}{ Neointimal hyperplasia } \\
\hline \multicolumn{2}{|l|}{ CTO PCI } \\
\hline Resolving proximal cap ambiguity & Often using a side-branch \\
\hline \multicolumn{2}{|l|}{ Delineating proximal cap morphology } \\
\hline
\end{tabular}

FFR, fractional flow reserve; CTO, chronic total occlusion; PCI, percutaneous coronary intervention. 


\section{Acknowledgments}

Funding: None.

\section{Footnote}

Provenance and Peer Review: This article was commissioned by the Guest Editor (Dennis T. L. Wong) for the series "Intracoronary Imaging" published in Cardiovascular Diagnosis and Therapy. The article has undergone external peer review.

Conflicts of Interest: Both authors have completed the ICMJE uniform disclosure form (available at http://dx.doi. org/10.21037/cdt.2020.01.15). The series "Intracoronary Imaging" was commissioned by the editorial office without any funding or sponsorship. SL reports personal fees from Boston Scientific, personal fees from Abbott Vascular, outside the submitted work. The authors have no other conflicts of interest to declare.

Ethical Statement: The authors are accountable for all aspects of the work in ensuring that questions related to the accuracy or integrity of any part of the work are appropriately investigated and resolved.

Open Access Statement: This is an Open Access article distributed in accordance with the Creative Commons Attribution-NonCommercial-NoDerivs 4.0 International License (CC BY-NC-ND 4.0), which permits the noncommercial replication and distribution of the article with the strict proviso that no changes or edits are made and the original work is properly cited (including links to both the formal publication through the relevant DOI and the license). See: https://creativecommons.org/licenses/by-nc-nd/4.0/.

\section{References}

1. Jang JS, Song YJ, Kang W, et al. Intravascular ultrasoundguided implantation of drug-eluting stents to improve outcome: a meta-analysis. JACC Cardiovasc Interv 2014;7:233-43.

2. Nerlekar N, Cheshire CJ, Verma KP, et al. Intravascular ultrasound guidance improves clinical outcomes during implantation of both first- and second-generation drug-eluting stents: a meta-analysis. EuroIntervention 2017;12:1632-42.

3. Serruys PW, Kogame N, Katagiri Y, et al. Clinical outcomes of state-of-the-art percutaneous coronary revascularisation in patients with three-vessel disease: twoyear follow-up of the SYNTAX II study. EuroIntervention 2019;15:e244-52.

4. Koskinas KC, Nakamura M, Raber L, et al. Current use of intracoronary imaging in interventional practice

- Results of a European Association of Percutaneous Cardiovascular Interventions (EAPCI) and Japanese Association of Cardiovascular Interventions and Therapeutics (CVIT) Clinical Practice Survey. EuroIntervention 2018;14:e475-84.

5. Nissen SE, Yock P. Intravascular ultrasound: novel pathophysiological insights and current clinical applications. Circulation 2001;103:604-16.

6. Mintz GS, Nissen SE, Anderson WD, et al. American College of Cardiology clinical expert consensus document on standards for acquisition, measurement and reporting of intravascular ultrasound studies: a report of the American College of Cardiology Task Force on Clinical Expert Consensus Documents (Committee to Develop a Clinical Expert Consensus Document on Standards for Acquisition, Measurement and Reporting of Intravascular Ultrasound Studies [IVUS]). J Am Coll Cardiol 2001;37:1478-92.

7. Bech GJ, De Bruyne B, Pijls NH, et al. Fractional flow reserve to determine the appropriateness of angioplasty in moderate coronary stenosis: a randomized trial. Circulation 2001;103:2928-34.

8. Tonino PA, De Bruyne B, Pijls NH, et al. Fractional flow reserve versus angiography for guiding percutaneous coronary intervention. N Engl J Med 2009;360:213-24.

9. De Bruyne B, Pijls NH, Kalesan B, et al. Fractional flow reserve-guided PCI versus medical therapy in stable coronary disease. N Engl J Med 2012;367:991-1001.

10. Mintz GS, Guagliumi G. Intravascular imaging in coronary artery disease. Lancet 2017;390:793-809.

11. Abizaid AS, Mintz GS, Mehran R, et al. Long-Term Follow-Up After Percutaneous Transluminal Coronary Angioplasty Was Not Performed Based on Intravascular Ultrasound Findings. Circulation 1999;100:256-61.

12. de la Torre Hernandez JM, Hernández Hernandez F, Alfonso F, et al. Prospective Application of Pre-Defined Intravascular Ultrasound Criteria for Assessment of Intermediate Left Main Coronary Artery Lesions. J Am Coll Cardiol 2011;58:351-8.

13. Mintz GS. Intravascular Imaging of Coronary Calcification and Its Clinical Implications. JACC: Cardiovascular Imaging 2015;8:461-71.

14. Mosseri M, Satler LF, Pichard AD, et al. Impact of 
vessel calcification on outcomes after coronary stenting. Cardiovasc Revasc Med 2005;6:147-53.

15. Kim SS, Yamamoto MH, Maehara A, et al. Intravascular ultrasound assessment of the effects of rotational atherectomy in calcified coronary artery lesions. Int J Cardiovasc Imaging 2018;34:1365-71.

16. Sahara M, Kirigaya H, Oikawa Y, et al. Soft plaque detected on intravascular ultrasound is the strongest predictor of in-stent restenosis: an intravascular ultrasound study. Eur Heart J 2004;25:2026-33.

17. Tanaka A, Kawarabayashi T, Nishibori Y, et al. No-reflow phenomenon and lesion morphology in patients with acute myocardial infarction. Circulation 2002;105:2148-52.

18. Nicholls SJ, Hsu A, Wolski K, et al. Intravascular ultrasound-derived measures of coronary atherosclerotic plaque burden and clinical outcome. J Am Coll Cardiol 2010;55:2399-407.

19. Stone GW, Maehara A, Lansky AJ, et al. A prospective natural-history study of coronary atherosclerosis. N Engl J Med 2011;364:226-35.

20. Cheng JM, Garcia-Garcia HM, de Boer SP, et al. In vivo detection of high-risk coronary plaques by radiofrequency intravascular ultrasound and cardiovascular outcome: results of the ATHEROREMO-IVUS study. Eur Heart J 2014;35:639-47.

21. Mintz GS, Popma JJ, Pichard AD, et al. Intravascular ultrasound predictors of restenosis after percutaneous transcatheter coronary revascularization. J Am Coll Cardiol 1996;27:1678-87.

22. Sakurai R, Ako J, Morino Y, et al. Predictors of edge stenosis following sirolimus-eluting stent deployment (a quantitative intravascular ultrasound analysis from the SIRIUS trial). Am J Cardiol 2005;96:1251-3.

23. Mintz GS, Painter JA, Pichard AD, et al. Atherosclerosis in angiographically "normal" coronary artery reference segments: An intravascular ultrasound study with clinical correlations. J Am Coll Cardiol 1995;25:1479-85.

24. Morino Y, Tamiya S, Masuda N, et al. Intravascular ultrasound criteria for determination of optimal longitudinal positioning of sirolimus-eluting stents. Circ J 2010;74:1609-16.

25. Oviedo C, Maehara A, Mintz GS, et al. Intravascular ultrasound classification of plaque distribution in left main coronary artery bifurcations: where is the plaque really located? Circ Cardiovasc Interv 2010;3:105-12.

26. Mintz GS, Popma JJ, Pichard AD, et al. Limitations of angiography in the assessment of plaque distribution in coronary artery disease: a systematic study of target lesion eccentricity in 1446 lesions. Circulation 1996;93:924-31.

27. Raber L, Mintz GS, Koskinas KC, et al. Clinical use of intracoronary imaging. Part 1: guidance and optimization of coronary interventions. An expert consensus document of the European Association of Percutaneous Cardiovascular Interventions. EuroIntervention 2018;14:656-77.

28. Uren NG, Schwarzacher SP, Metz JA, et al. Predictors and outcomes of stent thrombosis: an intravascular ultrasound registry. Eur Heart J 2002;23:124-32.

29. Cheneau E, Leborgne L, Mintz GS, et al. Predictors of subacute stent thrombosis: results of a systematic intravascular ultrasound study. Circulation 2003;108:43-7.

30. Okabe T, Mintz GS, Buch AN, et al. Intravascular ultrasound parameters associated with stent thrombosis after drug-eluting stent deployment. Am J Cardiol 2007;100:615-20.

31. de Jaegere P, Mudra H, Figulla H, et al. Intravascular ultrasound-guided optimized stent deployment. Immediate and 6 months clinical and angiographic results from the Multicenter Ultrasound Stenting in Coronaries Study (MUSIC Study). Eur Heart J 1998;19:1214-23.

32. Oemrawsingh PV, Mintz GS, Schalij MJ, et al. Intravascular ultrasound guidance improves angiographic and clinical outcome of stent implantation for long coronary artery stenoses: final results of a randomized comparison with angiographic guidance (TULIP Study). Circulation 2003;107:62-7.

33. Schiele F, Meneveau N, Vuillemenot A, et al. Impact of intravascular ultrasound guidance in stent deployment on 6-month restenosis rate: a multicenter, randomized study comparing two strategies-with and without intravascular ultrasound guidance. J Am Coll Cardiol 1998;32:320-8.

34. Moussa I, Moses J, Di Mario C, et al. Does the specific intravascular ultrasound criterion used to optimize stent expansion have an impact on the probability of stent restenosis? Am J Cardiol 1999;83:1012-7.

35. Chieffo A, Latib A, Caussin C, et al. A prospective, randomized trial of intravascular-ultrasound guided compared to angiography guided stent implantation in complex coronary lesions: the AVIO trial. Am Heart J 2013;165:65-72.

36. Russo RJ, Silva PD, Teirstein PS, et al. A randomized controlled trial of angiography versus intravascular ultrasound-directed bare-metal coronary stent placement (the AVID Trial). Circ Cardiovasc Interv 2009;2:113-23.

37. Parise H, Maehara A, Stone GW, et al. Meta-analysis of randomized studies comparing intravascular ultrasound versus angiographic guidance of percutaneous coronary 
intervention in pre-drug-eluting stent era. Am J Cardiol 2011;107:374-82.

38. Hong SJ, Kim BK, Shin DH, et al. Effect of Intravascular Ultrasound-Guided vs Angiography-Guided EverolimusEluting Stent Implantation: The IVUS-XPL Randomized Clinical Trial. JAMA 2015;314:2155-63.

39. Zhang J, Gao X, Kan J, et al. Intravascular Ultrasound Versus Angiography-Guided Drug-Eluting Stent Implantation: The ULTIMATE Trial. J Am Coll Cardiol 2018;72:3126-37.

40. Sonoda S, Morino Y, Ako J, et al. Impact of final stent dimensions on long-term results following sirolimuseluting stent implantation: serial intravascular ultrasound analysis from the sirius trial. J Am Coll Cardiol 2004;43:1959-63.

41. Hong MK, Mintz GS, Lee CW, et al. Intravascular ultrasound predictors of angiographic restenosis after sirolimus-eluting stent implantation. Eur Heart J 2006;27:1305-10.

42. Kang SJ, Ahn JM, Song H, et al. Comprehensive intravascular ultrasound assessment of stent area and its impact on restenosis and adverse cardiac events in 403 patients with unprotected left main disease. Circ Cardiovasc Interv 2011;4:562-9.

43. Choi SY, Witzenbichler B, Maehara A, et al. Intravascular ultrasound findings of early stent thrombosis after primary percutaneous intervention in acute myocardial infarction: a Harmonizing Outcomes with Revascularization and Stents in Acute Myocardial Infarction (HORIZONS-AMI) substudy. Circ Cardiovasc Interv 2011;4:239-47.

44. Sonoda S, Hibi K, Okura H, et al. Current clinical use of intravascular ultrasound imaging to guide percutaneous coronary interventions. Cardiovasc Interv Ther 2020;35:30-6.

45. Park DW, Ahn JM, Yun SC, et al. 10-Year Outcomes of Stents Versus Coronary Artery Bypass Grafting for Left Main Coronary Artery Disease. J Am Coll Cardiol 2018;72:2813-22.

46. Park SJ, Kim YH, Park DW, et al. Impact of intravascular ultrasound guidance on long-term mortality in stenting for unprotected left main coronary artery stenosis. Circ Cardiovasc Interv 2009;2:167-77.

47. Kim JS, Hong MK, Ko YG, et al. Impact of intravascular ultrasound guidance on long-term clinical outcomes in patients treated with drug-eluting stent for bifurcation lesions: data from a Korean multicenter bifurcation registry. Am Heart J 2011;161:180-7.

48. Kang SJ, Mintz GS, Kim WJ, et al. Preintervention angiographic and intravascular ultrasound predictors for side branch compromise after a single-stent crossover technique. Am J Cardiol 2011;107:1787-93.

49. Karacsonyi J, Alaswad K, Jaffer FA, et al. Use of Intravascular Imaging During Chronic Total Occlusion Percutaneous Coronary Intervention: Insights From a Contemporary Multicenter Registry. J Am Heart Assoc 2016. doi: 10.1161/ JAHA.116.003890.

50. Galassi AR, Sumitsuji S, Boukhris M, et al. Utility of Intravascular Ultrasound in Percutaneous Revascularization of Chronic Total Occlusions: An Overview. JACC Cardiovasc Interv 2016;9:1979-91.

51. Rathore S, Katoh O, Tuschikane E, et al. A novel modification of the retrograde approach for the recanalization of chronic total occlusion of the coronary arteries intravascular ultrasound-guided reverse controlled antegrade and retrograde tracking. JACC Cardiovasc Interv 2010;3:155-64.

52. Tanaka T, Okamura A, Iwakura K, et al. Efficacy and Feasibility of the 3-Dimensional Wiring Technique for Chronic Total Occlusion Percutaneous Coronary Intervention: First Report of Outcomes of the 3-Dimensional Wiring Technique. JACC Cardiovasc Interv 2019;12:545-55.

53. Kim BK, Shin DH, Hong MK, et al. Clinical Impact of Intravascular Ultrasound-Guided Chronic Total Occlusion Intervention With Zotarolimus-Eluting Versus BiolimusEluting Stent Implantation: Randomized Study. Circ Cardiovasc Interv 2015;8:e002592.

54. Tian NL, Gami SK, Ye F, et al. Angiographic and clinical comparisons of intravascular ultrasound- versus angiography-guided drug-eluting stent implantation for patients with chronic total occlusion lesions: twoyear results from a randomised AIR-CTO study. EuroIntervention 2015;10:1409-17.

55. Colombo A, Hall P, Nakamura S, et al. Intracoronary stenting without anticoagulation accomplished with intravascular ultrasound guidance. Circulation 1995;91:1676-88.

56. Mintz GS, Popma JJ, Pichard AD, et al. Arterial remodeling after coronary angioplasty: a serial intravascular ultrasound study. Circulation 1996;94:35-43.

57. Nissen SE, Tuzcu EM, Schoenhagen P, et al. Effect of intensive compared with moderate lipid-lowering therapy on progression of coronary atherosclerosis: a randomized controlled trial. JAMA 2004;291:1071-80.

58. Chhatriwalla AK, Nicholls SJ, Nissen SE. The ASTEROID trial: coronary plaque regression with highdose statin therapy. Future Cardiol 2006;2:651-4.

59. Nicholls SJ, Puri R, Anderson T, et al. Effect of 
Evolocumab on Progression of Coronary Disease in Statin-Treated Patients: The GLAGOV Randomized Clinical Trial. JAMA 2016;316:2373-84.

60. Sarno G, Onuma Y, Garcia Garcia HM, et al. IVUS radiofrequency analysis in the evaluation of the polymeric struts of the bioabsorbable everolimus-eluting device during the bioabsorption process. Catheter Cardiovasc Interv 2010;75:914-8.

Cite this article as: $\mathrm{Xu} \mathrm{J}, \mathrm{Lo} \mathrm{S}$. Fundamentals and role of intravascular ultrasound in percutaneous coronary intervention. Cardiovasc Diagn Ther 2020;10(5):1358-1370. doi: 10.21037/ cdt.2020.01.15
61. Hausmann D, Erbel R, Alibelli-Chemarin MJ, et al. The safety of intracoronary ultrasound. A multicenter survey of 2207 examinations. Circulation 1995;91:623-30.

62. Ali ZA, Maehara A, Généreux P, et al. Optical coherence tomography compared with intravascular ultrasound and with angiography to guide coronary stent implantation (ILUMIEN III: OPTIMIZE PCI): a randomised controlled trial. Lancet 2016;388:2618-28. 